\title{
Spirometry is underused in the diagnosis and monitoring of patients with chronic obstructive pulmonary disease (COPD)
}

This article was published in the following Dove Press journal:

International Journal of COPD

23 August 2013

Number of times this article has been viewed

\author{
Wai Cho Yu' \\ Sau Nga Fu² \\ Emily Lai-bun $\mathrm{Tai}^{3}$ \\ Yiu Cheong Yeung' \\ Kwok Chu Kwong' \\ Yui Chang' \\ Cheuk Ming Tam ${ }^{3}$ \\ Yuk Kwan Yiu \\ 'Department of Medicine and \\ Geriatrics, Princess Margaret Hospital, \\ Hong Kong; ${ }^{2}$ Department of Family \\ Medicine and Primary Healthcare, \\ Kowloon West Cluster, Hospital \\ Authority, Hong Kong; ${ }^{3}$ Tuberculosis \\ and Chest Service, Department of \\ Health, Government of Hong Kong, \\ Special Administrative Region, \\ Hong Kong
}

Correspondence: Wai Cho Yu Department of Medicine and Geriatrics, Princess Margaret Hospital, Hong Kong Tel +852 29903737

Fax +852 29903333

Email yuwc@ha.org.hk
Abstract: Spirometry is important in the diagnosis and management of chronic obstructive pulmonary disease (COPD), yet it is a common clinical observation that it is underused though the extent is unclear. This survey aims to examine the use of spirometry in the diagnosis and management of COPD patients in a district in Hong Kong. It is a cross-sectional survey involving four clinic settings: hospital-based respiratory specialist clinic, hospital-based mixed medical specialist clinic, general outpatient clinic (primary care), and tuberculosis and chest clinic. Thirty physician-diagnosed COPD patients were randomly selected from each of the four clinic groups. All of them had a forced expiratory volume in 1 second $\left(\mathrm{FEV}_{1}\right)$ to forced vital capacity ratio less than 0.70 and had been followed up at the participating clinic for at least 6 months for COPD treatment. Of 126 patients who underwent spirometry, six (4.8\%) did not have COPD. Of the 120 COPD patients, there were 111 males and mean post-bronchodilator FEV was $_{1}$ $46.2 \%$ predicted. Only 22 patients $(18.3 \%$ ) had spirometry done during diagnostic workup, and 64 patients $(53.3 \%)$ had spirometry done ever. The only independent factor predicting spirometry done ever was absence of old pulmonary tuberculosis and follow-up at respiratory specialist clinic. Age, sex, smoking status, comorbidities, duration of COPD, percentage predicted FEV , body mass index, 6-minute walking distance, and Medical Research Council dyspnea score were not predictive. We conclude that spirometry is underused in general but especially by nonrespiratory physicians and family physicians in the management of COPD patients. More effort at educating the medical community is urgently needed.

Keywords: guidelines, pulmonary function tests, specialist

\section{Introduction}

Chronic obstructive pulmonary disease (COPD) is characterized by advancing airflow obstruction and impairment of gaseous exchange resulting in progressive worsening of shortness of breath. The disease affects 65 million people worldwide and more than 12 million people in the US alone, and is it likely that these figures are grossly underestimated. ${ }^{1-3}$ More than 3 million people died from COPD in 2005, and it is predicted that mortality from this disease will continue to increase. ${ }^{2}$ In Hong Kong, the burden of COPD is also high, with high utilization of health care resources. ${ }^{4-6}$

Diagnosis of COPD rests on history, physical examination, chest radiograph, and the demonstration of airflow obstruction by spirometry. Although being criticized as overly simplistic, ${ }^{7,8}$ the spirometric finding of a post-bronchodilator forced expiratory volume in 1 second $\left(\mathrm{FEV}_{1}\right)$ to forced vital capacity $(\mathrm{FVC})$ ratio of less than 0.70 is still universally accepted as being diagnostic of significant airflow obstruction. ${ }^{1,9-11}$ Having made the diagnosis, one would like to assess the severity of the disease. 
Percentage predicted post-bronchodilator $\mathrm{FEV}_{1}$ is objective and reproducible, correlates well with disease severity, and is a good prognostic indicator. ${ }^{12,13}$ Furthermore, in the subsequent management of COPD, serial $\mathrm{FEV}_{1}$ can serve to follow the progress of the disease and provide guidance on treatment options in different stages of disease evolution.

It is therefore hardly surprising that all the major international COPD management guidelines mandate the use of spirometry in the initial diagnostic evaluation of patients with symptoms suggestive of COPD. ${ }^{1,10,11}$ However, it is a common observation in daily clinical practice that spirometry is very much underused. In fact, it is not uncommon for patients with severe COPD to have the disease diagnosed and treated for many years, yet have no spirometry done. To examine the extent of the problem, we set out to conduct a survey to observe the use of spirometry in COPD management.

\section{Methods}

This is a cross-sectional survey carried out in Kwai Tsing area, Hong Kong, with a population of approximately 570,000 . The objective of the survey was to observe what investigations and treatments COPD patients actually receive. Results on treatment aspects have been reported in another paper, ${ }^{14}$ and this one focuses on use of spirometry.

There were a total of eleven clinics in the public sector which care for COPD patients in the area under study. Very few COPD patients had long-term follow-up in the private sector. The public sector clinics were grouped according to their specialty, and 30 COPD subjects were selected from each group: group 1, one respiratory specialist clinic; group 2 , four general medical specialist clinics; group 3, five family medicine clinics or general outpatient clinics (primary care clinics); group 4, one tuberculosis and chest clinic.

For groups 1-3, subject lists were generated from the Hospital Authority Clinical Data Analysis and Reporting System in June 2008. Subjects were randomly selected from the list and were invited to participate in the study by phone call. An appointment was given to verbally consenting subjects to attend a study visit. Recruitment for each group stopped when 30 consenting and evaluable subjects for that group has been accrued. For group 4, since no patient list could be generated, COPD subjects were invited to participate in the study as they attended follow-up at the clinic; workflow was similar to the other groups.

At the study visit, subjects signed an informed consent form and were then checked for study entry criteria. Inclusion criteria were: (1) physician-diagnosed COPD, (2) post-bronchodilator $\mathrm{FEV}_{1}$ to $\mathrm{FVC}$ ratio less than 0.70 ,
(3) regular follow-up at the participating clinic for treatment of stable COPD for at least 6 months, and (4) willing and able to comply with study requirements such as performing spirometry and 6-minute walk test. Exclusion criteria were: (1) non-COPD diagnosis as judged by the investigator; (2) subjects attending regular follow-up at another clinic and attending the participating clinic irregularly for acute exacerbation of COPD or other problems; (3) history of significant coexisting chronic lung disease such as asthma, pulmonary fibrosis, bronchiectasis, and restrictive lung disease; and (4) history of lung resection.

When the subjects satisfied all inclusion and none of the exclusion criteria, collection of demographic data, medical data, and smoking history was done. The use of spirometry in the diagnosis and subsequent management of COPD were recorded from the medical records and word of mouth was not accepted. Use of spirometry for diagnostic workup is defined as spirometry done within 6 months before or after making the COPD diagnosis. If the subject had spirometry done in the study center within the previous year, the result was used for study analysis, otherwise spirometry was done for all subjects during the study visit. This was done according to American Thoracic Society/European Respiratory Society 2005 recommendations, ${ }^{15}$ and the subject must not have had COPD exacerbation in the preceding 4 weeks. Local reference values were used for $\mathrm{FEV}_{1}$ and other spirometric parameters. ${ }^{16}$ Measurement of body mass index, 6-minute walking distance, ${ }^{17}$ and dyspnea level using the Medical Research Council dyspnea scale ${ }^{18}$ were also done.

After the study visit, subjects continued to attend regular follow-up at their original clinic. Summaries of a subject's clinical findings and/or treatment recommendations were supplied to the care giver on request.

Data were expressed as percentages, means, and medians, as appropriate. During univariate analysis to compare variables between the groups with and without spirometry ever performed, independent-samples $t$-test, Mann-Whitney $U$-test, and chi-square test were used as appropriate. If there was at least one group with expected count less than 5 when comparing distributions, Fisher's exact test was used. McNemar's test was used to compare the proportion of patients with spirometry and/or chest radiograph done at diagnosis/ever because the samples were deemed related. With the same standpoint, mean time before study visit of spirometry and chest X-ray were compared by $t$-test for two related samples. Those variables with $P$-value less than 0.2 in univariate analysis were subject to logistic regression by backward elimination method, with "significant level of 
stay" set to 0.10 . A $P$-value of less than 0.05 was considered statistically significant.

The study was approved by the Research Ethics Committee of Hospital Authority Kowloon West Cluster (reference: KW/EX/07-092) and the Ethics Committee of the Department of Health (reference: L/M 243/2008).

\section{Results}

Subject recruitment started in June 2008 and was completed in June 2009. A total of 144 subjects were invited to participate in the study. Fourteen subjects refused to participate; two were excluded because of concomitant lung disease, and one died before attending a study visit. The remaining 127 subjects attended study visits. Six were excluded because the diagnosis was judged to be non-COPD, and one was excluded because of failed spirometry. Finally, the data of 120 subjects with 30 from each clinic group were analyzed (Figure 1).

For the six subjects who were excluded during study visits for non-COPD diagnosis, all had a FEV to $_{1} \mathrm{FV}$ ratio greater than 0.70 , and five had a post-bronchodilator $\mathrm{FEV}_{1}$ percentage predicted higher than $80 \%$. Three had chronic bronchitic symptoms and were given the diagnosis of "bronchitis not otherwise specified," one had mild bronchiectasis, which could explain the symptom of chronic productive cough, while one had no bronchitic symptoms and was considered free from lung disease. The remaining female subject had a very low post-bronchodilator $\mathrm{FEV}_{1}$ of only $40 \%$ predicted, and she likely suffered from interstitial lung disease.

For the final 120 subjects, males predominated (111, $92.5 \%$ ), and mean age was 71.8 years. All were ethnic
Chinese, and all but six were either current or ex-smokers. Mean post-bronchodilator $\mathrm{FEV}_{1}$ was $46.2 \%$ predicted, and stratification into Global Initiative for Chronic Obstructive Lung Disease (GOLD) stages ${ }^{1}$ was: stage I, 10 (8.3\%); stage II, 38 (31.7\%); stage III, 46 (38.3\%); and stage IV, 26 (21.7\%). Other characteristics are shown in Table 1.

Sixty-four subjects $(53.3 \%)$ had spirometry ever done prior to study visit and 56 subjects did not. Table 1 presents data comparing demographic and medical data of the two groups. By univariate analysis, factors significantly associated with spirometry ever done were absence of old pulmonary tuberculosis, more severe disease (lower post-bronchodilator $\mathrm{FEV}_{1}$ percentage predicted and more severe GOLD stage), post-bronchodilator FVC percentage predicted, and clinic group 1 (versus groups 2, 3, and 4 combined). All other factors did not show statistically significant differences between the two groups. These include age, sex, smoking status, number of pack-years, former worker occupation, presence of significant comorbidities, duration of COPD, body mass index, exercise capacity (6-minute walking distance), and severity of dyspnea (Medical Research Council dyspnea score). In the subsequent multivariate analysis (Table 2), absence of old pulmonary tuberculosis and clinic group 1 significantly favored spirometry ever done, whereas GOLD stage, post-bronchodilator $\mathrm{FEV}_{1}$ percentage predicted, postbronchodilator FVC percentage predicted, peak expiratory ratio $\left(\mathrm{FEV}_{1} / \mathrm{FVC}\right)$, and $\mathrm{FEV}_{1}$ bronchodilator reversibility change in volume and percentage were not.

Table 3 shows the use of spirometry compared with chest radiograph, which is another important investigation in the
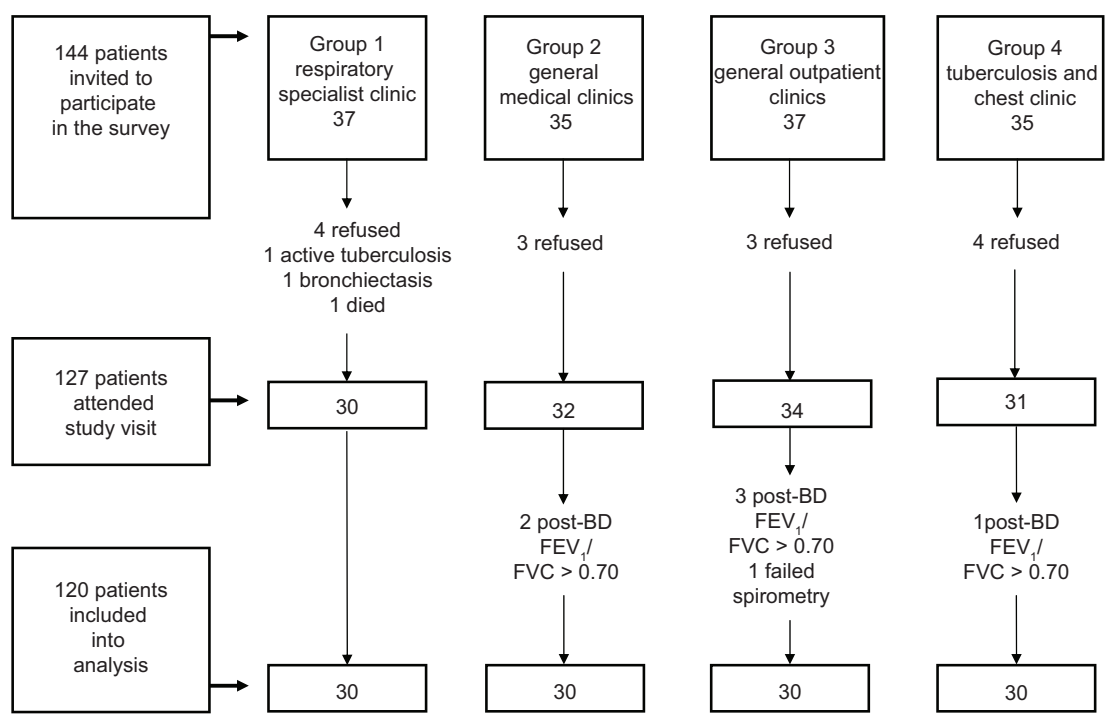

Figure I Subject screening and recruitment summary.

Abbreviations: post-BD, post-bronchodilator; FEV , forced expiratory volume in I second; FVC, forced vital capacity. 
Table I Subject characteristics according to whether spirometry was ever performed

\begin{tabular}{|c|c|c|c|c|}
\hline Parameter & All $(N=120)$ & $\begin{array}{l}\text { With spirometry } \\
(\mathrm{n}=64)\end{array}$ & $\begin{array}{l}\text { Without spirometry } \\
(n=56)\end{array}$ & $P$-value \\
\hline Male:female & $111: 9$ & $58: 6$ & $53: 3$ & \\
\hline Male \% & $92.5 \%$ & $90.6 \%$ & $94.6 \%$ & $0.500^{\mathrm{a}}$ \\
\hline Age (mean, SD) & $71.8(8.02)$ & $71.7(7.04)$ & $71.9(8.82)$ & $0.883^{b}$ \\
\hline \multicolumn{5}{|l|}{ Smoking status } \\
\hline Never (n, \%) & $6(5 \%)$ & $4(6.3 \%)$ & $2(3.6 \%)$ & - \\
\hline Ex- $(n, \%)$ & $88(73.3 \%)$ & $48(75.0 \%)$ & 40 (7I.4\%) & - \\
\hline Current (n, \%) & $26(21.7 \%)$ & $12(18.8 \%)$ & $14(25 \%)$ & $0.407^{c}$ \\
\hline Pack-year (mean, SD) & $58.4(37.90)$ & $59.2(36.46)$ & $57.6(39.45)$ & $0.226^{\mathrm{d}}$ \\
\hline Worker occupation (n, \%) & $70(58.3)$ & $38(59.4)$ & $32(57.1 \%)$ & $0.805^{c}$ \\
\hline With old PTB $(n, \%)$ & $20(16.7 \%)$ & $5(7.8 \%)$ & $15(26.8 \%)$ & $0.005^{c}$ \\
\hline \multicolumn{5}{|l|}{ Significant medical comorbidity ${ }^{\mathrm{e}}$} \\
\hline At least one $(n, \%)$ & $72(60.0 \%)$ & 38 (59.4\%) & $34(60.7 \%)$ & $0.88 I^{c}$ \\
\hline Duration of COPD in years (mean, SD) & $9.8(7.55)$ & $9.6(6.18)$ & I0.I (8.86) & $0.431^{d}$ \\
\hline Post-BD FEV, percentage predicted (mean, SD) & $46.2(19.89)$ & $41.0(17.57)$ & $52.1(20.72)$ & $0.002^{\mathrm{d}}$ \\
\hline Post-BD FVC percentage predicted (mean, SD) & $71.7(22.86)$ & $66.6(20.62)$ & $77.5(24.07)$ & $0.027^{d}$ \\
\hline Peak expiratory ratio (FEV /FVC) (mean, SD) & $0.476(0.131)$ & $0.455(0.126)$ & $0.499(0.133)$ & $0.067^{d}$ \\
\hline \multicolumn{5}{|l|}{ FEV, bronchodilator reversibility (mean, SD) } \\
\hline Volume change $(\mathrm{mL})$ & $122.5(\mid 24.1)$ & $104.8(113.9)$ & $142.7(133.0)$ & $0.145^{d}$ \\
\hline Percentage change & $5.5(5.5)$ & $4.8(5.0)$ & $6.4(5.9)$ & $0.137^{d}$ \\
\hline GOLD stage (n, $\%$ of stage group, $95 \% \mathrm{Cl}$ ) & & & & $0.003^{\mathrm{a}}$ \\
\hline Stage I & 10 & $2(20 \%,-4.8 \%-44.8 \%)$ & $8(80 \%)$ & \\
\hline Stage II & 38 & $15(39.5 \%, 24 \%-55 \%)$ & $23(60.5 \%)$ & \\
\hline Stage III & 46 & 27 (58.7\%, 44.5\%-72.9\%) & $19(41.3 \%)$ & \\
\hline Stage IV & 26 & 20 (76.9\%, 60.7\%-93.1\%) & $6(23.1 \%)$ & \\
\hline BMI (mean, SD) & $22.2(3.84)$ & $22.4(3.56)$ & $22.1(4.13)$ & $0.479^{d}$ \\
\hline $6 \mathrm{MWD}$ in meters (mean, SD) & $253.7(77.20)$ & $256.7(77.53)$ & $250.2(76.68)$ & $0.650^{\mathrm{b}}$ \\
\hline MRC dyspnea score (median, IQR) & $2(1)$ & $2(1)$ & $2(1)$ & $0.94 I^{d}$ \\
\hline \multicolumn{5}{|l|}{ Clinic location } \\
\hline Respiratory specialist clinic (group I) & 30 & $29(96.7 \%)$ & I (3.3\%) & $0.000^{c}$ \\
\hline Medical specialist clinics (group 2) & 30 & $20(66.7 \%)$ & $10(33.3 \%)$ & \\
\hline Primary care clinics (group 3) & 30 & $8(26.7 \%)$ & $22(73.3 \%)$ & \\
\hline Tuberculosis and chest clinic (group 4) & 30 & 7 (23.3\%) & $23(76.7 \%)$ & \\
\hline Groups $2+3+4$ & 90 & 35 (38.9\%) & $55(61.1 \%)$ & \\
\hline
\end{tabular}

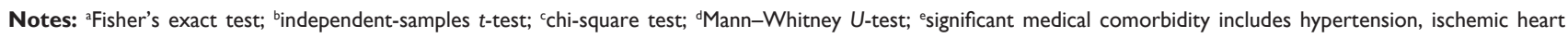
disease, congestive heart failure, cardiac arrhythmia, cerebrovascular disease, diabetes mellitus with or without complications, chronic liver disease, chronic renal disease, obstructive sleep apnea, rheumatoid arthritis, tumors, malignancies, depression, and schizophrenia.

Abbreviations: SD, standard deviation; PTB, pulmonary tuberculosis; COPD, chronic obstructive pulmonary disease; post-BD, post-bronchodilator; FEV , forced expiratory volume in I second; FVC, forced vital capacity; GOLD, Global Initiative for Chronic Obstructive Lung Disease; BMI, body mass index; 6 MWD, 6-minute walking distance; MRC, Medical Research Council; Cl, confidence interval; IQR, interquartile range.

management of COPD. Overall, spirometry was performed in only 22 subjects $(18.3 \%)$ during diagnostic workup, and 64 subjects $(53.3 \%)$ had it ever done. For those who had spirometry ever done, the mean time interval before study visit was 39.1 months, with a range of 1-132 months. By contrast, chest radiograph was done at diagnostic workup in 96 subjects $(80 \%)$ and was ever done in 117 subjects (97.5\%). Mean time of last order of chest radiograph prior to study visit was much shorter at 12.1 months, with a range of 0.5-84.0 months. All the differences were highly statistically significant.

The timeframe of performing spirometry prior to study visit is depicted in Figure 2. The figure shows that at all time points, group 1 had a higher proportion of patients having spirometry performed compared with the other groups. Of note is that within 2 years preceding the study visit, 21 subjects (70\%) in group 1 had spirometry done, whereas values for groups 2,3 , and 4 were $6(20 \%), 3(10 \%)$, and 1 $(3.3 \%)$ respectively.

\section{Discussion}

To our knowledge this is the first cross-sectional survey to examine the use of spirometry in the management of diagnosed COPD patients in Hong Kong. Our data shows that only $18.3 \%$ of COPD patients in Kwai Tsing district had spirometry done at diagnosis and $53.3 \%$ had it ever done, indicating 
Table 2 Factors associated with spirometry ever done multivariate analysis (logistic regression by backward elimination)

\begin{tabular}{|c|c|c|c|}
\hline & $\begin{array}{l}\text { Adjusted } \\
\text { odds ratio }\end{array}$ & $95 \% \mathrm{Cl}$ & $P$-value \\
\hline $\begin{array}{l}\text { With old pulmonary } \\
\text { tuberculosis }\end{array}$ & 0.138 & $(0.026-0.726)$ & 0.019 \\
\hline \multicolumn{4}{|c|}{ Clinic location (compared with group I) } \\
\hline Group 2 & 0.049 & $(0.005-0.472)$ & 0.009 \\
\hline Group 3 & 0.009 & $(0.00 \mathrm{I}-0.092)$ & 0.000 \\
\hline Group 4 & 0.008 & $(0.00 I-0.080)$ & 0.000 \\
\hline $\begin{array}{l}\text { GOLD stage (compared } \\
\text { with stage I) }\end{array}$ & & & NS \\
\hline $\begin{array}{l}\text { Post-BD FEV } \\
\text { percentage predicted }\end{array}$ & & & NS \\
\hline $\begin{array}{l}\text { Post-BD FVC } \\
\text { percentage predicted }\end{array}$ & & & NS \\
\hline $\begin{array}{l}\text { Peak expiratory } \\
\text { ratio }\left(\mathrm{FEV}_{1} / \mathrm{FVC}\right)\end{array}$ & & & NS \\
\hline $\begin{array}{l}\mathrm{FEV} \text {, bronchodilator } \\
\text { reversibility change }(\mathrm{mL})\end{array}$ & & & NS \\
\hline $\begin{array}{l}\mathrm{FEV} \text {, bronchodilator } \\
\text { reversibility change (\%) }\end{array}$ & & & NS \\
\hline
\end{tabular}

Abbreviations: $\mathrm{Cl}$, confidence interval; GOLD, Global Initiative for Chronic Obstructive Lung Disease; post-BD, post-bronchodilator; $\mathrm{FEV}_{1}$, forced expiratory volume in I second; FVC, forced vital capacity; NS, non significant.

inconsistent use. Interestingly, this problem appears to be commonplace across the world. A Swedish survey found that of 533 newly diagnosed COPD patients, $59 \%$ had spirometry performed and $45 \%$ had post-bronchodilator spirometry values. An FEV to $\mathrm{FVC}$ ratio of less that 0.70 was found in only $30 \%$ of patients. ${ }^{19}$ The Canadian CAGE study involving 1,090 COPD patients from Quebec and Ontario found that $56 \%$ had spirometry ever done..$^{20}$ In the People's Republic of China, a large survey involving 20,245 COPD subjects from seven provinces/cities showed that only $6.5 \%$ were tested with spirometry. ${ }^{21}$ A recent audit of the US Veterans Health Administration involving 93,724 newly diagnosed COPD patients found that only $36.7 \%$ had spirometry performed 2 years before or 6 months after the diagnosis was made. ${ }^{22}$ This was despite the (then) recent inclusion of this investigation as a performance measure by the United States National Committee for Quality Assurance. ${ }^{22}$

Table 3 Comparison of use of spirometry and chest radiograph

\begin{tabular}{llll}
\hline & Spirometry & $\begin{array}{l}\text { Chest } \\
\text { radiograph }\end{array}$ & P-value \\
\hline Done at diagnosis & $22(18.3 \%)$ & $96(80 \%)$ & $0.000^{\mathrm{a}}$ \\
Done ever & $64(53.3 \%)$ & $117(97.5 \%)$ & $0.000^{\mathrm{a}}$ \\
Mean time before study & 39.1 & 12.1 & $0.000^{\mathrm{b}}$ \\
visit (months) & & & $\mathrm{NA}$ \\
Range (months) & $\mathrm{I}-\mathrm{I} 32$ & $0.5-84.0$ & $\mathrm{~N}$
\end{tabular}

Notes: aMcNemar's test; ${ }^{b}$-test for two related samples; NA, not applicable.
When we tried to look for factors that favor performance of spirometry, we found as expected that clinic location is the most important factor. This finding suggests that patient factors were not responsible for alerting a doctor to order spirometry in COPD management. Rather, the medical specialty appear to be the important factor, with respiratory physicians most inclined to order spirometry followed by general physicians followed by primary care physicians and tuberculosis and chest physicians. Similar findings were reported by Lee et al, ${ }^{23}$ in which use of spirometry for newly diagnosed COPD patients was 3.3 times higher for those visiting pulmonologists compared with those visiting primary care alone. One possible explanation for these findings is that patients followed up at respiratory specialist clinics have more severe disease (data not shown), but statistical analysis of our data has indicated that disease severity is not an important factor in this regard. A more plausible explanation might be that specialization towards respiratory medicine increases awareness of the need for spirometry and the proficiency in interpreting the spirometry results. Overseas surveys have observed that use of office spirometry is associated with many practical problems, including availability of spirometer and space, need for calibration and standardization of the spirometer, ${ }^{24}$ and availability of adequately trained staff. ${ }^{25}$ Confidence in interpretive skills appears to be an important factor in primary care ${ }^{26}$ and was not improved by computerized expert report systems. ${ }^{27}$ Chest radiograph on the other hand is readily available and routinely reported by radiologists, and its higher utilization compared with spirometry may lend support to the above speculation.

A surprise finding is the significant association of the presence of old pulmonary tuberculosis with lack of spirometric assessment. There have not been similar reports elsewhere, and the cause for this finding is not immediately obvious. One would have thought that old pulmonary tuberculosis should be an additional prompt for doctors to order spirometry since there is another lung pathology on top of COPD. However, if doctors can ignore factors like smoking status, significant dyspnea, and poor exercise tolerance, old pulmonary tuberculosis as a prompt to order spirometry may not be a realistic expectation.

Damarla et $\mathrm{al}^{28}$ reported in a retrospective study that of patients admitted to hospital over an 8-year period, only $31 \%$ of COPD patients ( $36 \%$ with concomitant respiratory failure) had spirometry done, whereas $78 \%$ had two-dimensional echocardiography done for patients with congestive heart failure. For the 219 patients with both conditions, $48 \%$ had two-dimensional echocardiography as the only 


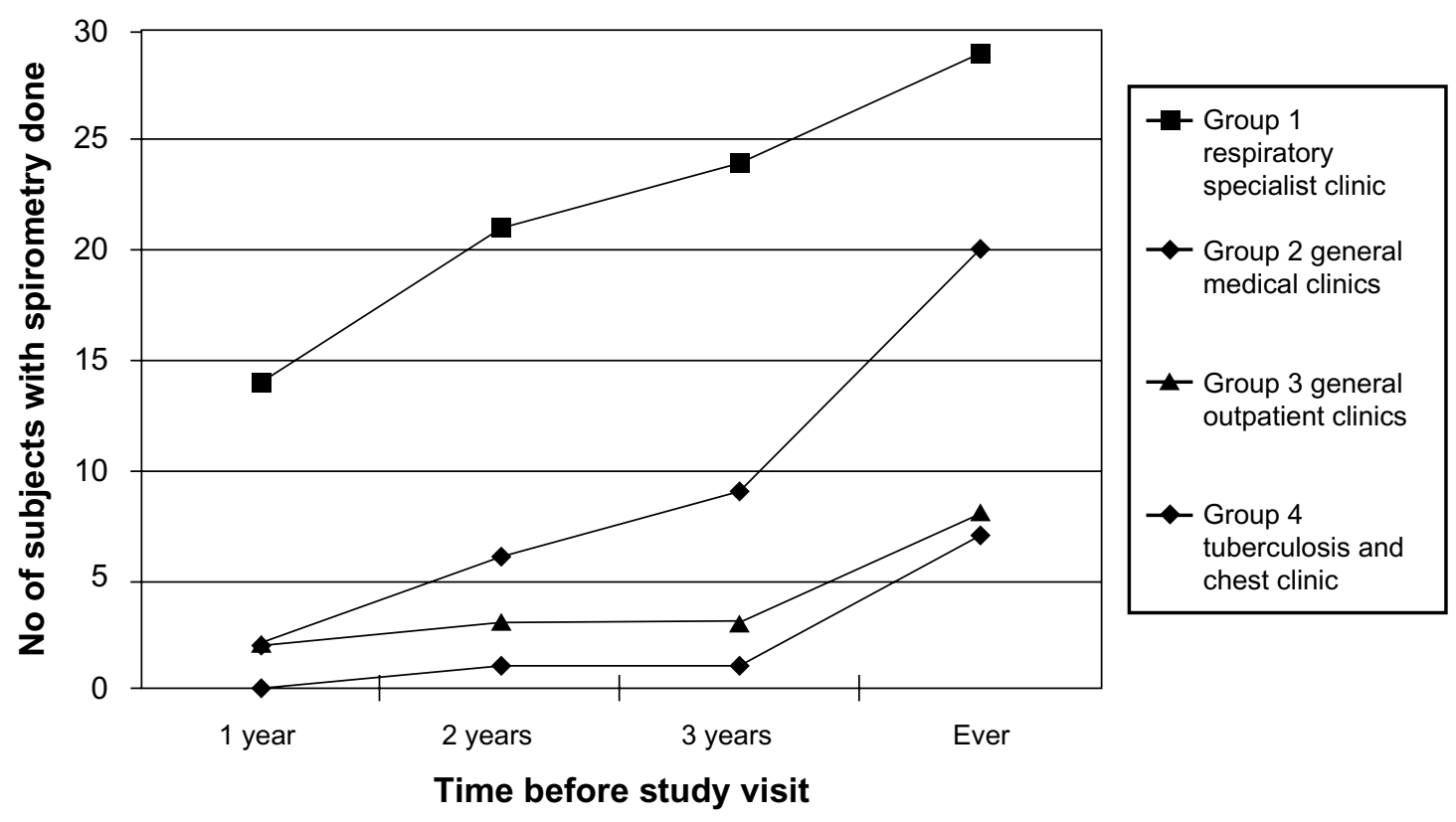

Figure 2 Timeframe of performing spirometry according to groups.

confirmatory test, $34 \%$ had both tests performed, and only $2 \%$ had spirometry alone. The result is disturbing, since the two tests are very comparable in availability, complexity, ease of interpretation, and utility for treatment guidance. These findings once again suggest that physicians are insufficiently informed on the importance of spirometry in COPD management.

It would appear then that educational workshops with information on the indications, interpretation, and implications of spirometry results, and hands-on workshops on lung function testing may contribute towards solving the current problem. Some published reports focusing on primary care show good short-term results, ${ }^{29,30}$ but longer-term improvements remain to be seen. Published reports on spirometry workshops with a wider medical audience are lacking. On a different front, spirometry campaigns such as the 2010 World COPD and Spirometry Day may also be useful in increasing public awareness, putting pressure on the medical community to use the test appropriately and consistently. Finally, the setting up of incentive systems like the Quality and Outcomes Framework for general practitioners in the United Kingdom is likely to be helpful.

Our study has the strength that subjects are enrolled from different clinic types, which allows comparisons between them. Also, unlike surveys based on diagnostic and procedural coding, all of our subjects attended a study visit and had clinical and spirometry assessment done to confirm the diagnosis of COPD and whether spirometry was done previously. The study is however limited by its relatively small sample size and its limited location in Hong Kong. Larger, territory-wide studies would be able to give more precise information on the overall situation. Another limitation is the small proportion of female subjects, which probably reflects the low prevalence of smoking amongst Hong Kong women and which severely limits the applicability of our results to this gender.

In conclusion, spirometry is inconsistently used in the management of COPD in Kwai Tsing region, Hong Kong, with most of the problem being seen in nonrespiratory and primary care clinics. A combination of monitoring systems on the use of spirometry in COPD, more education on the importance of spirometry in COPD management, and assistance in interpretation of spirometry results may bring about improvements.

\section{Acknowledgments}

We would like to thank Ms Polly Pang and Ms Eva Tam for coordinating the study, Ms Carmen Cheung for performing the lung function tests, Ms Candy Leung for performing the 6-minute walk tests, and Mr WL Wong for statistical support.

\section{Disclosure}

This study was supported by a research grant from GlaxoSmithKline (HK) Ltd. The authors have no other conflicts of interest. 


\section{References}

1. Global Initiative for Chronic Obstructive Lung Disease, Inc. Global strategy for the diagnosis, management, and prevention of chronic obstructive pulmonary disease - 2013 update. Available from: http:// www.goldcopd.org/uploads/users/files/GOLD_Report_2013_Feb20. pdf. Accessed April 8, 2013.

2. World Health Organization [homepage on the Internet]. Burden of COPD. Geneva: World Health Organization. Available from: http:// www.who.int/respiratory/copd/burden/en. Accessed June 27, 2013.

3. Mannino DM, Buist AS. Global burden of COPD: risk factors, prevalence, and future trends. Lancet. 2007;370:765-773.

4. Chan-Yeung M, Lai CK, Chan KS, et al. The burden of lung disease in Hong Kong: a report from the Hong Kong Thoracic Society. Respirology. 2008;13 Suppl 4:S133-S165.

5. Ko FW, Woo J, Tam W, et al. Prevalence and risk factors of airflow obstruction in an elderly Chinese population. Eur Respir J. 2008;32(6): 1472-1478.

6. Lau AC, Ip MS, Lai CK, et al. Variability of the prevalence of undiagnosed airflow obstruction in smokers using different diagnostic criteria. Chest. 2008;133(1):42-48.

7. Hardie JA, Buist AS, Vollmer WM, et al. Risk of overdiagnosis of COPD in asymptomatic elderly nonsmokers. Eur Respir J. 2002;20(5): $1117-1122$.

8. Cerveri I, Coriscico AG, Accoridini S, et al. Underestimation of airflow obstruction among young adults using FEV1/FVC $<70 \%$ as a fixed cutoff: a longitudinal evaluation of clinical and functional outcomes. Thorax. 2008;63(12):1040-1045.

9. Johannessen A, Lehmann S, Omenaas ER, et al. Postbronchodilator spirometry reference values in adults and implications for disease management. Am J Respir Crit Care Med. 2006;173(12):1316-1325.

10. Qaseem A, Wilt TJ, Weinberger SE, et al. Diagnosis and management of stable chronic obstructive pulmonary disease: a clinical practice guideline update from the American College of Physicians, American College of Chest Physicians, American Thoracic Society, and European Respiratory Society. Ann Intern Med. 2011;155(3):179-191.

11. National Institute for Health and Care Excellence. Chronic obstructive pulmonary disease: management of chronic obstructive pulmonary disease in adults in primary and secondary care - 2010 update. Available from: http://guidance.nice.org.uk/CG101. Accessed April 8, 2013.

12. Anthonisen NR, Wright EC, Hodgkin JE. Prognosis in chronic obstructive pulmonary disease. Am Rev Respir Dis. 1986;133(1):14-20.

13. Burrows B. The course and prognosis of different types of chronic airflow limitation in a general population sample from Arizona: comparison with the Chicago "COPD” series. Am Rev Respir Dis. 1989;140(3 Pt 2):S92-S94.

14. Yu WC, Tai LB, Fu SN, et al. Treatment of patients with chronic obstructive pulmonary disease as practiced in a defined Hong Kong community: a cross-sectional pilot survey. Hong Kong Med J. 2011;17(4):306-314.
15. Miller MR, Hankinson J, Brusasco V, et al; ATS/ERS Task Force. Standardisation of spirometry. Eur Respir J. 2005;26(2):319-338.

16. Ip MS, Ko FW, Lau AC, et al. Updated spirometric reference values for adult Chinese in Hong Kong and implications on clinical utilization. Chest. 2006;129(2):384-392.

17. Guyatt GH, Pugsley SO, Sullivan MJ, Thompson PJ, Berman L, Jones NJ. Effect of encouragement on walking test performance. Thorax. 1984;39:818-822.

18. Bestell JC, Paul EA, Garrod R, et al. Usefulness of the Medical Research Council (MRC) dyspnea scale as a measure of disability in patients with chronic obstructive pulmonary disease. Thorax. 1999;54(7): 581-586.

19. Arne M, Lisspers K, Stallberg B, et al. How often is diagnosis of COPD confirmed with spirometry? Respir Med. 2010;104(4):550-556.

20. Bourbeau J, Sebaldt RJ, Day A, et al. Practice patterns in the management of chronic obstructive pulmonary disease in primary care practice: the CAGE study. Can Respir J. 2008;15(1):13-19.

21. Zhong N, Wang C, Yao W, et al. Prevalence of chronic obstructive pulmonary disease in China: a large population-based survey. Am J Respir Crit Care Med. 2007;176(8):753-760.

22. Joo MJ, Lee TA, Weiss KB. Geographic variation of spirometry use in newly diagnosed COPD. Chest. 2008;134:38-45.

23. Lee TA, Bartle B, Weiss KB. Spirometry use in clinical practice following diagnosis of COPD. Chest. 2006;129:1509-1515.

24. Eaton T, Withy S, Garrett JE, et al. Spirometry in primary care practice: the importance of quality assurance and the impact of spirometry workshops. Chest. 1999;116:416-423.

25. Poels PJ, Schermer TR, Jacobs A, et al. Variation in spirometry utilization between trained general practitioners in practices equipped with a spirometer. Scand J Prim Health Care. 2006;24:81-87.

26. Bolton $\mathrm{CE}$, Ionescu AA, Edwards $\mathrm{PH}$, et al. Attaining a correct diagnosis of COPD in general practice. Respir Med. 2005;99:493-500.

27. Poels PJ, Schermer TR, Schellekens DP, et al. Impact of a spirometry expert system on general practitioners' decision making. Eur Respir J. 2008;31:84-92.

28. Damarla M, Celli BR, Mullerova HX, Pinto-Plata VM. Discrepancy in the use of confirmatory tests in patients hospitalized with the diagnosis of chronic obstructive pulmonary disease or congestive heart failure. Respir Care. 2006;51(10):1120-1124.

29. Kaminsky DA, March TW, Bachand M, Irvin CG. Knowledge and use of office spirometry for the detection of chronic obstructive pulmonary disease by primary care physicians. Respir Care. 2005;50(12): 1639-1648.

30. Yawn BP, Enright PL, Lemanske RF Jr, et al. Spirometry can be done in family physicians' offices and alters clinical decisions in management of asthma and COPD. Chest. 2007;132(10):1162-1168.
International Journal of COPD

\section{Publish your work in this journal}

The International Journal of COPD is an international, peer-reviewed journal of therapeutics and pharmacology focusing on concise rapid reporting of clinical studies and reviews in COPD. Special focus is given to the pathophysiological processes underlying the disease, intervention programs, patient focused education, and self management protocols.

\section{Dovepress}

This journal is indexed on PubMed Central, MedLine and CAS. The manuscript management system is completely online and includes a very quick and fair peer-review system, which is all easy to use. Visit http://www.dovepress.com/testimonials.php to read real quotes from published authors. 